\title{
Congenital narrowing of the cervical spinal canal
}

\author{
JEFFREY T. KESSLER \\ From the Department of Neurology, The New York Hospital-Cornell Medical Center, New York, New York \\ 10021, U.S.A.
}

SYNOPSIS The clinical and laboratory findings in six patients with congenital narrowing of the cervical spinal canal and neurological symptoms are described. A variable age of onset and an entirely male occurrence were found. Signs and symptoms of spinal cord dysfunction predominated in all but one patient. Symptoms were produced in five patients by increased physical activity alone. Congenital narrowing of the cervical spinal canal may result in cord compression without a history of injury and occasionally without evidence of significant bony degenerative changes. The clinical features may be distinguishable from those found in cervical spondylosis without congenital narrowing. Intermittent claudication of the cervical spinal cord appears to be an important feature of this syndrome. Surgery improved four out of five people.

The cervical spinal canal is a triangular tube that diminishes in size from top to bottom (Burrows, 1963). The transverse (interpedicular) diameter is nearly twice that of the sagittal (anteroposterior) diameter. Thus, the most critical radiographic measurement in the cervical region in evaluating for cord compression is the sagittal diameter (Boijsen, 1954; Wolf et al., 1956; Penning, 1962). Average values for the sagittal diameter of the cervical spinal canal in normal individuals are $22-23 \mathrm{~mm}$ for $\mathrm{Cl}$; 20-20.5 mm for $\mathrm{C} 2$; 18.3-18.5 mm for $\mathrm{C} 3$, and 17.0-17.8 mm for C4 to C7 vertebral levels with little difference among the lower four segments (Wolf et al., 1956; Burrows, 1963; Lurati and Mertens, 1971). Values below $14 \mathrm{~mm}$ are uncommon and fall below two standard deviations at any cervical segment (Lurati and Mertens, 1971). Burrows (1963) found only six values below $14 \mathrm{~mm}$ in 2100 individual segmental measurements in 300 normal subjects and Wolf et al. (1956) found 21 such values in 1400 measurements in 200 normal subjects.

The importance of the constitutional sagittal diameter of the cervical spinal canal to the subsequent development of spondylotic myelopathy is well documented. Patients with congenital narrowing of the cervical spinal canal

(Accepted 17 June 1975.) can be found in most large series of this disorder (Payne and Spillane, 1957; Epstein et al., 1963; Crandall and Batzdorf, 1966; Symon and Lavender, 1967; Galera and Tovi, 1968; Wilkinson et al., 1969; Eyssette et al., 1970; Godlewski, 1972; Nurick, 1972a). However, clinical features peculiar to congenitally narrowed canals have not been noted in previous studies (Hinck et al., 1964; Hinck and Sachdev, 1966; Moiel et al., 1970; Lurati and Mertens, 1971). The present study reports, in six cases of congenital narrowing of the cervical spinal canal, clinical and radiographic findings which distinguish this group from the more common type of cervical myelopathy due to spondylosis.

\section{METHOD}

Since no record coding category for congenital spinal stenosis existed, 990 charts from The New York Hospital coded for cervical arthritis, cervical laminectomy, and hypertrophy of the ligamentum flavum during 1968 to 1973 and 184 charts coded for cervical laminectomy from 1963 to 1967 were reviewed. Six patients were found whose radiographic studies indicated congenital narrowing; two of these were examined personally. Patients were considered to have congenital cervical spinal canal narrowing if the constitutional sagittal diameter on a standard lateral radiograph was less than $14 \mathrm{~mm}$. Measurements were made from the posterior margin 
of the vertebral body to the cortical line at the site of fusion of the spinous process and the laminae. Plain films, tomograms and myelograms were reviewed with staff neuroradiologists.

CASE 1 (NYH 1333207) A 39 year old male taxicab driver presented with difficulty in walking for two or three months. He was well until three months before admission when he noted cramps in both calves awakening him at night and lasting about 30 seconds. Six to eight weeks before admission he noted increasing weakness in both lower extremities, especially climbing stairs. Numbness lasting about 15 minutes developed after exercise and was greater in the right leg than the left.

General physical examination was unremarkable. Neurological examination revealed $4 / 5$ strength in the hamstrings, hip abductors, and hip flexors with increased muscle tone in both legs. Sensory examination disclosed only an inconsistent response to pin prick below T11 dermatome. Gait was spastic and 'scissors-like'. Reflexes were $2+$ in the upper extremities, with $3+$ knee jerks and $4+$ ankle jerks and bilateral extensor plantar responses. No pain or limitation of neck movement was found. There was no anal wink but the cremasteric responses were intact. Cervical spine radiographs revealed a narrow canal measuring $13 \mathrm{~mm}$ in the neutral position at $\mathrm{C} 4$ vertebra. Lumbar iodophendylate (Pantopaque) myelography revealed an almost complete block from $\mathrm{C} 3$ to $\mathrm{C} 7$ vertebral levels, with no evidence of osteophytes, ridges, or disc herniation. The CSF protein was $0.85 \mathrm{~g} / \mathrm{l}$ and the sugar $2.33 \mathrm{mmol} / \mathrm{l}$. There were two mononuclear cells per cubic $\mathrm{mm}$. Only a bulging dura mater was found at surgery despite careful search for other anomalies. Five months postoperatively his gait had improved to normal and only mild hyperreflexia remained with flexor plantar responses.

CASE 2 (NYH 1170119) A 47 year old man had a 12 to 18 month history of urinary frequency and evidence of incomplete voiding on pyelography. He had noted intermittent neck ache over the six to 12 months before admission, as well as decreased ability to sustain an erection. The urinary symptoms were exacerbated by taking alcohol and by shovelling snow. No other medical history was obtained. Physical examination revealed only a slightly enlarged prostrate. Neurological examination revealed brisk deep tendon reflexes at the triceps and in both lower extremities. The rest of the examination was normal.

Cervical spine films revealed a congenitally narrow canal measuring as small as $10 \mathrm{~mm}$ at C6 vertebra. At myelography, mild to moderate de- generative changes were noted at $\mathrm{C} 3-4, \mathrm{C} 4-5$, and C5-6 intervertebral spaces which produced a considerable degree of obstruction of the subarachnoid space with probable spinal cord compression at these levels. The CSF protein was $0.71 \mathrm{~g} / 1$ and the sugar $3.05 \mathrm{mmol} / \mathrm{l}$. There was one mononuclear cell per cubic mm. At surgery, a total cervical laminectomy uncovered a thinned translucent dura mater which bulged as the laminectomy was done. No epidural fat was found.

No immediate change was noted postoperatively and the patient was lost to follow-up.

CASE 3 (NYH 118905) A 53 year old magistrate had been well until three weeks before admission when he noted unsteadiness on his feet and occasional cramp in his legs. His daughter had thought that he seemed unsteady when climbing stairs and dancing for the past year, though the patient denied this. Two days before admission, while doing 'situps', he suddenly developed weakness of both upper and lower extremities without pain, numbness, or paraesthesias. There was no history of neck pain, headache, bowel or bladder symptoms.

General physical examination was unremarkable. Neurological examination revealed mild to moderate quadriparesis with spasticity, slightly greater on the left, without wasting or fasciculations. His gait was broad-based and ataxic with bilateral circumduction, left greater than right. Position sense was moderately symmetrically diminished in all four extremities. Vibration sense was decreased to the pelvis and sensation to pin and temperature stimulation were intact. Light touch sensation was slightly decreased in a C8-T1 dermatome distribution bilaterally. Reflexes were $3+$ in the upper extremities and $4+$ in the lower extremities with bilateral extensor plantar and Hoffman responses.

Cervical spine films revealed intervertebral disc space narrowing with degenerative changes and anterior spur formation involving $\mathrm{C} 2, \mathrm{C} 3$, and $\mathrm{C} 4$ vertebrae with narrowing of the intervertebral foramina and posterior spur formation at $\mathrm{C} 2, \mathrm{C} 3$, and C5 vertebrae on the left and C5 and C6.vertebrae on the right. Marked narrowing of the anteroposterior canal diameter which appeared congenital in nature was noted and was maximal at $\mathrm{Cl}$ vertebra where it measured less than $11 \mathrm{~mm}$.

Myelography revealed degenerative changes at $\mathrm{C} 2-\mathrm{C} 3, \mathrm{C} 3-\mathrm{C} 4, \mathrm{C} 4-\mathrm{C} 5$, and $\mathrm{C5}-\mathrm{C} 6$ intervertebral spaces with considerable narrowing of the subarachnoid space due to osteophytes and a congenitally narrow canal. At $\mathrm{Cl}$ vertebra the sagittal diameter was less than $11 \mathrm{~mm}$ with even more marked narrowing of the subarachnoid space. The CSF contained no cells and gave a $1+$ Pandy reaction. At 
surgery the $\mathrm{C} 3, \mathrm{C} 4, \mathrm{C} 5, \mathrm{C} 6$, and $\mathrm{C} 7$ vertebrae were found to be quite thin. There was no epidural fat and the cord was compressed. $\mathrm{C} 2$ vertebra was thick and $\mathrm{Cl}$ even thicker, markedly compressing the cord at the foramen magnum. A complete cervical laminectomy was performed and postoperatively the patient was able to walk with the occasional aid of a single crutch.

CASE 4 (NYH 1352457) A 65 year old seaman had been well until 10 days before admission when he spontaneously developed numbness in both hands with difficulty in buttoning his clothes and picking up coins. Two days later he developed weakness in both legs with a staggering gait and numbness in the feet. He denied bladder symptoms but became constipated. He also noticed sharp pain in his neck which was non-radiating, worsened by lying down, and possibly improved by movement.

General physical examination was unremarkable. Neurological examination revealed difficulty in sitting upright, mild diffuse weakness of the upper and lower extremities, and increased tone in the legs. The vibratory threshold was increased in the arms and legs along with decreased sensation to twopoint, stereognostic, and graphaesthetic stimuli in the left hand. Decreased rapid alternating movements were found in all four extremities with slight impairment of point to point testing. His gait was spastic. The Romberg sign was absent. There was no pain or limitation of neck motion.

Cervical spine radiographs showed a narrowed spinal canal measuring 12-13 $\mathrm{mm}$ throughout. Lumbar myelography revealed a narrow spinal canal throughout with termination of the iodophendylate column at the level of $\mathrm{C} 4$ vertebra. The $\mathrm{C} 4-\mathrm{C} 5$, $\mathrm{C} 5-\mathrm{C} 6$, and $\mathrm{C} 6-\mathrm{C} 7$ root sleeves were prominent. A cisternal myelogram revealed a block at $\mathrm{C} 2-\mathrm{C} 3$ intervertebral space with some posterior and lateral epidural indentation thought to be caused by hypertrophied ligamentum flavum. The lumbar CSF contained no cells and had a protein of $0.45 \mathrm{~g} / \mathrm{l}$ and a sugar content of $4.05 \mathrm{mmol} / \mathrm{l}$. Because of the development during myelography of quadriplegia and a left T7 and right T8 dermatome sensory level, immediate complete cervical laminectomy was carried out which revealed the bone to be very tight over a paper-thin dura mater. Bits of ligamentum flavum were adherent to the dura mater.

Postoperatively the patient improved rapidly. Several months later his examination revealed only minimal left-sided weakness and bilateral hyperreflexia. He walked without assistance and denied sphincter difficulty.

CASE 5 (NYH 959187) A 15 year old male student was well until three years before admission when, while swimming in shallow (waist deep) water, he suddenly became unable to move his arms, legs, or trunk and had to be pulled from the water by a friend. The patient recovered within 10 to $20 \mathrm{sec}-$ onds. For the next several weeks he had 'pins and needles' in his hands, arms, shoulders, and across the back of his neck and an 'itchy' uncomfortable sensation when the skin was touched. He thought his arms were somewhat weak for about one week after the episode. Over the ensuing three years he noted one other occasion of sudden weakness in both arms when attempting to catch a football pass. He experienced pain in both arms for several seconds but was then able to continue playing without difficulty. Six weeks before admission while at football practice he struck his forehead on a tackling dummy and fell to the ground without loss of consciousness but unable to move his neck, trunk, or extremities for about 20 seconds. He had weakness and paraesthesia of the arms for about two minutes. He subsequently had several other such episodes when hyperextending his neck against the tackling dummy with initial flaccidity and weakness lasting 10 to 15 seconds and a one to two hour period for complete recovery.

$\mathrm{He}$ was large, muscular and healthy except for slightly exaggerated deep tendon reflexes. Passive neck hyperextension produced only a slight dull sensation at $\mathrm{C} 7$ vertebra.

Cervical spine films including extreme flexion, extension, and tomography were reportedly normal. Lumbar myelography revealed free flow to the lower cervical region. Persistent incomplete filling of the subarachnoid space on both sides due to marked narrowing of the bony canal without widening of the cord was seen throughout this area. His myelogram which was done in 1963, had been lost but it was clear from the description of the radiographic findings that he had congenital stenosis of his cervical canal.

At surgery a complete cervical laminectomy was performed and a firm bony ridge running transversely between the $\mathrm{C} 3$ and $\mathrm{C} 4$ vertebral area protruding three to four $\mathrm{mm}$ into the spinal canal was found. He was unchanged postoperatively and four years later on follow-up was found to be playing college football; he had had no more abnormal episodes and the results of neurological examination were normal.

CASE 6 (NYH 1249886) A 33 year old physician had a four to six month history of intermittent paraesthesias of the palmar aspect of the fourth and fifth digits of the left hand lasting one to two minutes. He had noticed only a mild 'stiff neck' inter- 
mittently before this while doing calisthenics including 'bridging' exercises at karate practice. This involved hyperextension and weight bearing on the cervical spine. Two to three months later he noted paraesthesias over the palm and radial aspect of the left forearm, and also occasional paraesthesias of the index finger of the right hand. The intermittent pain in the cervical area increased and radiated to the right paraspinal interscapular area. He denied precipitation of symptoms by neck movement in the beginning, but eventually hyperextension exacerbated the paraesthesias.

General physical examination was unremarkable as was the neurological examination.

Cervical spine films with tomography revealed congenital narrowing of the cervical canal to $13 \mathrm{~mm}$ which was further narrowed to $11-12 \mathrm{~mm}$ at $\mathrm{C} 5-\mathrm{C} 6$ interspace by an osteophyte.

No further studies were performed and the patient stopped performing calisthenics and hyperextension exercises, using running as his main form of exercise. His symptoms gradually decreased over two to three months and eventually he noticed only an occasional finger paraesthesia in the left hand and occasional neck ache.

\section{DISCUSSION}

Little information is available concerning the factors involved in the production of a congenitally narrowed spinal canal. Ossification centres appear at about nine weeks' gestation in each half of the yet unclosed neural arch and in the centrum of the vertebral body. Enchondral calcification may then continue to the 16th year, though union of most bony components is complete within a few years of birth (Warkany, 1971; Angevine, 1973). In achondroplastic dwarfs, premature fusion between the ossification centres of the vertebral body and the halves of the arch results in a decrease in the sagittal and transverse diameter of the canal (Duvoisin and Yahr, 1962; Hinck et al., 1962). An increase in periosteal bone can further narrow the canal (Duvoisin and Yahr, 1962). Measurement of the sagittal diameter of the cervical spinal canal in normal children indicates that from the age of 3 to 18 years the average increase is less than $3 \mathrm{~mm}$, indicating that most growth occurs before the age of 3 years (Hinck et al., 1962). Measurements in 18 year olds are similar to adult values (Hinck et al., 1964). It would seem likely, therefore, that factors which act to pro- duce a congenitally narrow canal do so between the third month of gestation and the third year of life. It has been suggested that excess secretion of growth hormone early in development might play a role by prematurely closing the ossification centres (Godlewski, 1972), though evidence to support this contention is lacking.

Associated congenital anomalies-for example, fused or block vertebrae-which have been reported in up to $10 \%$ of patients with spondylosis (Brain et al., 1952; Stoops and King, 1962; Crandal and Batzdorf, 1966) have not been noted in association with congenital narrowing of the canal. However, delineation of the vertebral bodies occurs well before fusion of the neural arch during early gestation (Ehrenhaft, 1943), so that processes affecting the bodies might spare the arch and thereby lessen the chances of such an association.

Clinical fEatures Sex A notable feature in this series is that all six patients are male. Thirteen out of 15 previously described patients with congenital stenosis and myelopathy were also male (Hinck et al., 1964; Hinck and Sachdev 1966; Moiel et al., 1970; Lurati and Mertens, 1971). It is of note that Lurati and Mertens (1971) found congenital narrowing at the levels of $\mathrm{C} 3$, $\mathrm{C} 4$, and $\mathrm{C} 5$ vertebrae only in males but were unable to detect a sex difference in a limited sample of C6 and C7 vertebrae. This sexual predilection cannot be explained,solely on the basis of a narrower canal in males, since in randomly selected normal subjects the sagittal diameter of the cervical spinal canal is usually smaller in women than in men, although the differences are generally less than $1 \mathrm{~mm}$ (Boijsen, 1954; Payne and Spillane, 1957; Burrows, 1963). Further, in congenital stenosis of the lumbar spinal canal a similar male preponderance has been found in symptomatic patients requiring surgery, though there appears to be little or no sex difference in the size of the canal diameter in normal subjects (Verbiest, 1955; Jones et al., 1968; Nelson, 1973; Roberson et al., 1973).

In cervical spondylotic myelopathy, Nurick (1972a) found that the canal must be narrower in women than in men to produce equal symptoms, possibly due to the greater incidence of spondylotic changes in men. However, the male predominance in this series could not be ascribed 
solely to the greater incidence of spondylotic changes in men (Irvine et al., 1965), since significant degenerative changes were not seen in cases 1 and 4 .

Age The ages of onset ranged from 15 to 65 years. However, the sample is too limited to allow further comment on the importance of age.

Signs and symptoms Neck pain occurred in three patients but did not correlate well with the extent of degenerative change, the degree of narrowing, or the severity of the neurological disability, a feature common to cervical spondylosis as well.

Brachial radiculopathy occurred in three patients but was the sole complaint in only one. Neurological signs of nerve root disease were absent in all but one. Cord compression was the dominant feature of the first five cases. Therefore, as in purely spondylotic myelopathy, 'developmental stenosis may compromise the capacity of the spinal canal without diminishing the size of the neural foramina' (Hinck and Sachdev, 1966).

The myelopathic symptoms seen in this series were of two types: (1) sudden development of myelopathy without regression; (2) brief transient episodes lasting minutes to hours. Both types could be induced by increased physical activity alone without apparent trauma or neck hypertension.

Mechanism of intermittent symptoms The brief, intermittent symptoms observed in these patients seem to be uncommon in cervical spondylosis, since exacerbations in the latter disease are not 'fleeting and recurrent' but are 'prolonged for weeks or months' and then tend to subside (Spillane and Lloyd, 1952; Lees and Turner, 1963). Intermittent spinal cord ischaemia or 'claudication' is thought to be a rare entity usually associated with either luetic or atherosclerotic involvement of the aorta and radicular spinal arteries or more rarely a herniated intervertebral disc (Jellinger and Neumayer, 1969).

However, the occurrence of spinal cord 'claudication' with cervical lesions appears to have an anatomical basis. Fibres of both the corticospinal and spinothalamic tracts are situated in the lateral white columns. The blood supply to these regions is derived from perpendicular perforators of the pial anastomatic arterial network on the cord surface (Breig et al., 1966; Turnbull, 1973). It is thought that these vessels are most vulnerable during compression of the cord in an anteroposterior direction (Breig et al., 1966), which could occur with sagittal narrowing of the spinal canal. The coronal venous plexus drains roughly similar areas (Aminoff et al., 1974) so that interference with venous drainage could also be an important factor.

By comparison, patients with congenital narrowing of the lumbar spinal canal frequently present with intermittent symptoms of cauda equina dysfunction induced by increased physical activity and disappearing within minutes to hours at rest (Verbiest, 1955; Jones et al., 1968; Pennal and Schatzker, 1971; Wilson et al., 1971 ; Nelson, 1973), whereas patients with compression of the roots of the cauda equina who have constitutionally normal-sized canals rarely develop an intermittent claudication syndrome (Wilson et al., 1971). It has been suggested that the pathogenesis of symptoms in lumbar narrowing is due to the inability of large vessels to dilate in the tight canal during exercise (Wilson et al., 1971) or to interference with the microvascular circulation by stretching of neural tissue secondary to increased lumbar lordosis (Nelson, 1973). Venous obstruction with stagnant hypoxia secondary to raised CSF pressure during exercise has also been proposed (Kavanaugh et al., 1968).

In this context, there are two general mechanisms by which intermittent symptoms of 'claudication' might be produced. There could either be an absolute reduction in total blood flow to the cord during exercise or, on the other hand, blood flow to the cord may fail to increase appropriately with increased activity.

Total blood flow to the cord might fall during exercise due to decreased peripheral vascular resistance and increased peripheral blood flow producing a 'steal' of blood from a cramped or compressed cord particularly in the crucial areas noted. This sort of 'steal' phenomenon has been postulated by Oliver et al. (1973) in two patients with spinal cord arteriovenous malformations who developed post-prandial paraparesis. One of these patients also developed cord symptoms 
after exercise that were similar to those induced post-prandially. The authors suggested a similar mechanism in women with cord arteriovenous malformations whose signs increased during pregnancy and regressed after delivery (Newman, 1958). However, evidence to support this 'steal' hypothesis has been found lacking by others (Kaufman et al., 1970; Aminoff et al., 1974).

It is also possible that appropriately situated spondylotic changes or untoward neck movement might reduce total cord blood flow by compromising radicular feeding vessels to the spinal cord (Taylor, 1964; Breig et al., 1966) and/or the cord microvascular circulation (Turnbull, 1973). But, this is unlikely to be the sole factor involved since intermittent symptoms of spinal cord ischaemia or 'claudication' developed in some patients who did not have significant spondylotic changes or a history of unusual neck movement. Finally, when a complete block exists, a Valsalva manoeuvre during exercise might further collapse strategic venous drainage and produce stagnant hypoxia to selected areas (Kavanaugh et al., 1968). On the other hand, the blood supply of the spinal cord has been shown to autoregulate in much the same manner as the brain (Turnbull, 1973; Griffiths, 1973a, b, c). While total cerebral blood flow probably does not increase significantly during exercise (Zobl et al., 1965; Lassen, 1974), significant focal increases in blood flow have been demonstrated during increased physical or mental activity (Olesen, 1971; Risberg and Ingvar, 1973). If focal increases in spinal cord blood flow also normally occur during exercise, ischaemic cord symptoms might be precipitated in a cramped canal that prevents the necessary vasodilatation in potentially vulnerable areasfor example, the lateral white columns.

Treatment A number of studies (Crandall and Batzdorf, 1966; Verbiest and Geuzse, 1966; Guidetti and Fortuna, 1969; Nurick, 1972b; Phillips, 1973) in recent years have recommended the anterior surgical approach for the operative management of cervical spondylotic myelopathy, especially for disease restricted to one or two segments. However, such a procedure may not be beneficial in patients with congenitally narrowed canals and has even led to complications (Galera and Tovi, 1968; Guidetti and
Fortuna, 1969; Phillips, 1973). The most adverse reports (Galera and Tovi, 1968) on the anterior surgical approach contain a high incidence $(62 \%)$ of patients with congenitally narrowed canals. A wide laminectomy has been suggested as the best approach to afford adequate decompression of the cord in congenital narrowing of the cervical spinal canal (Godlewski, 1972). In the current series, four of five patients treated by decompressive laminectomy improved.

Congenital stenosis of the cervical spinal canal is often distinguishable clinically as well as radiographically from 'pure' cervical spondylosis. Cognizance of this syndrome is important because of the different treatment from 'pure' cervical spondylosis. Therefore, radiographs of potential surgical candidates should be carefully assessed since congenital narrowing can occur at one, more than one, or all segments.

The author is indebted to Professors Fred Plum and Jerome Posner at Cornell and Stuart Cook and John Prineas at the New Jersey Medical School for their valuable suggestions and to Mrs Rose Jefferson for typing the manuscript.

\section{REFERENCES}

Aminoff, M. J., Barnard, R. O., and Logue, V. (1974). The pathophysiology of spinal vascular malformations. Journal of the Neurological Sciences, 23, 255-263.

Angevine, J. B. (1973). Clinically relevant embryology of the vertebral column and spinal cord. Clinical Neurosurgery, 20, 96-102.

Boijsen, E. (1954). The cervical spinal canal in intraspinal expansive processes. Acta Radiologica, 42, 101-115.

Brain, W. R., Northfield, D., and Wilkinson, M. (1952). The neurological manifestations of cervical spondylosis. Brain, 75, 187-225.

Breig, A., Turnbull, I., and Hassler, O. (1966). Effect of mechanical stresses on the spinal cord in cervical spondylosis. Journal of Neurosurgery, 25, 45-56.

Burrows, E. H. (1963). The sagittal diameter of the spinal canal in cervical spondylosis. Clinical Radiology, 17, 77-86.

Crandal, P. H., and Batzdorf, U. (1966). Cervical spondylotic myelopathy. Journal of Neurosurgery, 25, 57-66.

Duvoisin, R. C., and Yahr, M. D. (1962). Compressive spinal cord and root syndromes in achondroplastic dwarfs. Neurology (Minneap.), 12, 202-207.

Ehrenhaft, J. L. (1943). Development of the vertebral column as related to certain congenital and pathological changes. Surgery, Gynecology, and Obstetrics, 76, 282-292.

Epstein, J. A., Epstein, B. S., and Lavine, L. S. (1963). Cervical spondylotic myelopathy. Archives of Neurology, 3, 307-317.

Eyssette, M., Aimard, G., Bochu, M., Thierry, A. (1970). A propos des stenoses du canal cervical: sa mesure chez cinquante sujets indemnes de myelopathies. Journal de Médecine de Lyon, 51, 909-915. 
Galera, R., and Tovi, D. (1968). Anterior disc excision with interbody fusion in cervical spondylotic myelopathy and rhizopathy. Journal of Neurosurgery, 28, 305-310.

Godlewski, St. (1972). Les myelopathies par stenose cervicale et par cervicarthrose. Cahiers de Médecine, 13, 1069-1083.

Griffiths, I. R. (1973a). Spinal cord blood flow in dogs 1. the 'normal' flow. Journal of Neurology, Neurosurgery, and Psychiatry, 36, 34-41.

Griffiths, I. R. (1973b). Spinal cord blood flow in dogs 2. the effect of the blood gases. Journal of Neurology, Neurosurgery, and Psychiatry, 36, 43-49.

Griffiths, I. R. (1973c). Spinal cord blood flow in dogs: the effect of blood pressure. Journal of Neurology, Neurosurgery, and Psychiatry, 36, 914-920.

Guidetti, B., and Fortuna, A. (1969). Long-term results of surgical treatment of myelopathy due to cervical spondylosis. Journal of Neurosurgery, 30, 714-721.

Hinck, V. C., Gordy, P. D., and Storino, H. E. (1964). Developmental stenosis of the cervical spinal canal. Neurology (Minneap.), 14, 864-868.

Hinck, V. C., Hopkins, C. E., and Savara, B. S. (1962). Sagittal diameter of the cervical spinal in children. Radiology, 79, 97-108.

Hinck, V. C., and Sachdev, N. S. (1966). Developmental stenosis of the cervical spinal canal. Brain, 89, 27-36.

Irvine, D. H., Foster, J. B., Newell, D. J., and Klukvin, B. N. (1965). Prevalence of cervical spondylosis in a general practice. Lancet, 1, 1089-1092.

Jellinger, K., and Neumayer, E. (1969). Claudication of the spinal cord and cauda equina. Handbook of Clinical Neurology, vol. 12, pp. 507-547. Edited by P. J. Vinken, and G. W. Bruyn. North Holland: Amsterdam.

Jones, R. A. C., Salford, and Thomson, J. L. G, (1968). The narrow lumbar canal. Journal of Bone and Joint Surgery, 50B, 595-605.

Kaufman, H. H., Ommaya, A. K., DiChiro, G., and Doppman, J. L. (1970). Compression vs 'steal': the pathogenesis. of symptoms in arteriovenous malformations of the spinal cord. Archives of Neurology, 23, 173-178.

Kavanaugh, G. J., Svien, H. J., Holman, C. B., and Johnson, R. M. (1968). 'Pseudo-claudication' syndrome produced by compression of the cauda equina. Journal of the American Medical Association, 206, 2477-2481.

Lassen, N. A. (1974). Control of cerebral circulation in health and disease. Circulation Research, 34, 749-760.

Lees, F., and Turner, J. W. A. (1963). Natural history and prognosis of cervical spondylosis. British Medical Journal, 2, 1607-1610.

Lurati, M., and Mertens, H. G. (1971). Die Bedeutung der anlagebedingten enge des cervicalkanals fur die cervicale myelopathie. Zeitschrift fur Neurologie, 199, 46-66.

Moiel, B. H., Raso, E., and Waltz, T. A. (1970). Central cord syndrome resulting from congenital narrowness of the cervical spinal canal. Journal of Trauma, 10, 502-510.

Nelson, M. A. (1973). Lumbar spinal stenosis. Journal of Bone and Joint Surgery, 55B, 506-512.

Newman, M. J. D. (1958). Spinal angioma with symptoms in pregnancy. Journal of Neurology, Neurosurgery, and Psychiatry, 21, 38-41.

Nurick, S. (1972a). The pathogenesis of the spinal cord disorder associated with cervical spondylosis. Brain, 95, 87100.

Nurick, S. (1972b). The natural history and the results of surgical treatment of the spinal cord disorder associated with cervical spondylosis. Brain, 95, 101-108.
Olesen, J. (1971). Contralateral focal increase of cerebral blood flow in man during arm work. Brain, 94, 635-646.

Oliver, A. D., Wilson, C. B., and Boldrey, E. B. (1973). Transient postprandial paresis associated with arteriovenous malformations of the spinal cord. Journal of Neurosurgery, 39, 652-655.

Payne, E. E., and Spillane, J. D. (1957). The cervical spine: an anatomico-pathological study of 70 specimens (using a special technique) with particular reference to the problem of cervical spondylosis. Brain, 80, 571-593.

Pennal, G. F., and Schatzker, J. (1971). Stenosis of the lumbar spinal canal. Clinical Neurosurgery, 18, 86-105.

Penning, L. (1962). Some aspects of plain radiography of the cervical spine in chronic myelopathy. Neurology (Minneap.), 12, 513-519.

Phillips, D. G. (1973). Surgical treatment of myelopathy with cervical spondylosis. Journal of Neurology, Neurosurgery, and Psychiatry, 36, 879-884.

Risberg, J., and Ingvar, D. H. (1973). Patterns of activation in the grey matter of the dominant hemisphere during memorizing and reasoning: A study of regional cerebral blood flow changes during psychological testing in a group of neurologically normal patients. Brain, 96, 737-756.

Roberson, G. H., Llewellyn, H. J., and Taveras, J. M. (1973), The narrow lumbar spinal canal syndrome. Radiology, 107. 89-97.

Spillane, J. D., and Lloyd, G H. T. (1952). The diagnosis of lesions of the spinal cord in association with 'osteoarthritic' disease of the cervical spine. Brain, 75, 177-186.

Stoops, W. L., and King, R. B. (1962). Neural complications of cervical spondylosis: their response to laminectomy and foraminotomy. Journal of Neurosurgery, 19, 986-999.

Symon, L., and Lavender, P. (1967). The surgical treatment of cervical spondylotic myelopathy. Neurology (Minneap.), 17, 117-127.

Taylor, A. R. (1964). Vascular factors in the myelopathy associated with cervical spondylosis. Neurology (Minneap.), 14, 62-68.

Turnbull, I. M. (1973). Blood supply of the spinal cord: normal and pathological considerations. Clinical Neurosurgery, 20, 56-84.

Verbiest, H. (1955). Further experiences on the pathological influence of a developmental narrowness of the bony lumbar vertebral canal. Journal of Bone and Joint Surgery, 37B, 576-583.

Verbiest, H., and Geuse, H. D. (1966). Anterolateral surgery for cervical spondylosis in cases of myelopathy or nerveroot compression. Journal of Neurosurgery, 25, 611-622.

Warkany, J. (1971). The Spine in Congenital Malformations, pp. 916-929. Yearbook Medical Publishers: Chicago.

Wilkinson, H. A., LeMay, M. L., and Ferris, E. J. (1969). Roentgenographic correlations in cervical spondylosis. American Journal of Roentgenology, 105, 370-374.

Wilson, C. B., Ehni, G., and Grollmus, J. (1971). Neurogenic intermittent claudication. Clinical Neurosurgery, 18, 65-85.

Wolf, B. S., Khilnani, M., and Malis, L. (1956). The sagittal diameter of the bony cervical spinal canal and its significance in cervical spondylosis. Journal of the Mount Sinat Hospital, 23, 283-292.

Zobl, E. G., Talmers, F. N., Christensen, R. G., and Baer, L. J. (1965). Effect of exercise on the cerebral circulation and metabolism. Journal of Applied Physiology, 20, 12891293. 